\title{
Counseling for fetal heart disease-current standards and best practice
}

\author{
Alexander Kovacevic ${ }^{1}$, Michael Elsässer ${ }^{2}$, Herbert Fluhr ${ }^{2}$, Andreas Müller ${ }^{1}$, Sebastian Starystach ${ }^{3}$, \\ Stefan Bär ${ }^{3}$, Matthias Gorenflo ${ }^{1}$ \\ ${ }^{1}$ Department of Pediatric and Congenital Cardiology, Heidelberg University Hospital, Heidelberg, Germany; ${ }^{2}$ Department of Gynecology and \\ Obstetrics, Heidelberg University Hospital, Heidelberg, Germany; ${ }^{3}$ Max Weber Institute for Sociology, Ruprecht Karls University Heidelberg, \\ Heidelberg, Germany \\ Contributions: (I) Conception and design: A Kovacevic; (II) Administrative support: M Gorenflo; (III) Provision of study materials or patients: A \\ Kovacevic, M Elsässer, H Fluhr, A Müller, M Gorenflo; (IV) Collection and assembly of data: A Kovacevic, S Starystach, S Bär; (V) Data analysis and \\ interpretation: A Kovacevic, S Starystach, S Bär; (VI) Manuscript writing: All authors; (VII) Final approval of manuscript: All authors. \\ Correspondence to: Dr. Alexander Kovacevic. Department of Pediatric and Congenital Cardiology, Heidelberg University Hospital, Im Neuenheimer \\ Feld 430, 69120 Heidelberg, Germany. Email: Alexander.Kovacevic@med.uni-heidelberg.de.
}

\begin{abstract}
Congenital heart disease (CHD) is the most common cause of major congenital anomalies affecting newborns. Prenatal detection of CHD has been improving continuously during the last two decades due to technical advances and thus optimized fetal cardiac imaging. Besides the in-utero diagnosis of CHD effective parental counseling is an integral part of any Fetal Cardiology Program. However, studies on the most effective techniques are scarce, as well as data on empirical assessment of counseling and its effectiveness. In this review article, we summarize current guidelines from different international associations and societies. We provide an updated literature overview evaluating current standards of counseling with regard to parental needs. This includes ethical aspects, counseling for univentricular disease and in-utero cardiac interventions. We discuss our method to assess counseling success for fetal heart defects by exploring different analytical dimensions that may be considered helpful in order to improve efficacy. Finally, we present a proposal of how to optimize a setting for counseling based on the current literature and our own data. In summary, parental counseling for fetal heart disease is complex and multidimensional. Significant expertise in fetal cardiology and physiology, potential progression of CHD, postnatal treatment strategies and knowledge of long-term sequelae is necessary. A structured approach, together with continuous improvement of communicative skills, may lead to more effective counseling for parents following a diagnosis of CHD in the fetus.
\end{abstract}

Keywords: Fetal cardiology; congenital heart disease (CHD); counseling; interdisciplinary approach

Submitted Jul 14, 2020. Accepted for publication Aug 05, 2020.

doi: $10.21037 / \mathrm{tp}-20-181$

View this article at: http://dx.doi.org/10.21037/tp-20-181

\section{Introduction}

Effective parental counseling for prenatal congenital heart disease (CHD) is one of the main tasks for fetal cardiologists or maternal-fetal medicine (MFM) specialists after diagnosing CHD in the fetus. It has been shown to be a complex and multidimensional process with multiple factors affecting counseling success (1-3). In contrast relatively little research has been undertaken in this field (4). This is even more compelling as it is known that experiencing a diagnosis of CHD in the fetus is extremely stressful for parents leading to increased state anxiety and depression in a subset of mothers (5). Furthermore, increased maternal stress may affect fetal and child outcomes in terms of alterations in growth and/or neurocognitive development. Elevations of maternal cortisol levels due to 
stress may influence fetal development (6-11). Even though guidelines from different international associations exist, there still seems to be a need for improvement (12-17). Identifying modifiers for effective counseling is therefore worthy of exploration. Different parental needs have been specified and questionnaires have been published assessing effectiveness of counseling $(1-3,13,14)$. Prenatal diagnosis of CHD in the unborn child is undoubtedly a traumatic event for parents which may influence their emotions significantly and finally also their decision-making depending on the cardiac as well as potential extra-cardiac diagnoses $(5,18)$.

This article provides an updated literature review outlining the different recommendations by medical societies. We present results of studies evaluating counseling in this setting. Furthermore, we demonstrate our approach of assessing success of parental counseling for fetal CHD. Finally, we propose a setting of how to optimize counseling based on the current literature and our own data.

\section{Recommendations by international societies}

Different international medical societies have published on counseling after diagnosis of fetal CHD. The American Heart Association (AHA) has published a scientific statement on diagnosis and treatment of fetal cardiac disease (4). The Association for European Paediatric and Congenital Cardiology (AEPC) has issued specific recommendations for the practice of fetal cardiology (19). Finally, the International Society of Ultrasound in Obstetrics \& Gynecology (ISUOG) has made some very important statements on the association between neurodevelopmental delay and CHD and its impact on prenatal counseling $(20,21)$.

In general, parents should be counseled shortly after the fetal echocardiogram. Counselors may use diagrams of the diagnosed CHD, hand drawings, models, or online material to explain the heart disease and therapeutic options. Accordingly, a truthful picture of the prognosis, including long-term issues and re-operation rates need to be provided (4). The AEPC has stated that a pediatric cardiologist always must be involved, which firstly appears to be superfluous as logical (19). However, this is often not routinely performed in many European countries, as there are no strict recommendations by national societies. In our experience counseling in conjunction with an MFM specialist is extremely helpful and increases the quality of fetal care. Furthermore, the AEPC suggests moving parents into a separate counseling room to provide a quite setting. Afterwards, appropriate appointments for followup visits, or where applicable, to see other personnel such as geneticists, neonatologists and cardiac surgeons, need to be arranged.

ISUOG has focused on the important topic of neurodevelopmental issues of children diagnosed with CHD. It is proposed to state that the majority of neonates will do well. However, some will have neurological problems in the long-term, but the exact degree of neurodevelopmental delay cannot be predicted prenatally. Children with univentricular heart disease, e.g., Hypoplastic Left Heart Syndrome (HLHS), are at increased risk of neurodevelopmental delay, which always needs to be mentioned during counseling $(20,21)$. However, with comorbidities such as genetic anomalies the risk may even be higher.

In case of additional extra-cardiac anomalies or genetic syndromes the potential effect on treatment and prognosis needs to be delineated to the parents.

Potential diagnostic limitations must be discussed with parents. These may occur due to an unfavorable fetal position, maternal habitus, oligo- or polyhydramnios, or gestational age.

Finally, delivery, immediate postnatal management and expected treatment in the long-term need to be depicted.

\section{Identified parental needs for counseling}

Parental needs often differ from what specialists provide during counseling. In particular the child's quality of life as topic seems underrepresented, but also potential future lifetime surgeries and exercise limitations (12). Parents often are overburdened by complex anatomical details provided. They are more interested in their child's future functional outcome $(13,16)$.

After initial counseling, written information is valued by parents (14). While one group could show that repeated counseling sessions seem useful, others could not prove this finding, indicating that quality—not quantity—seems more important $(2,14)$. A separate counseling room to ensure a quite surrounding has been shown to be beneficial to achieve effective counseling, which should be uninterrupted and of adequate duration $(2,3)$. The value of internet-based information platforms is controversially discussed. While undoubtedly high-quality web-pages of e.g., Pediatric Heart Centers are reliable information sources, unfiltered onlinedata are often misleading $(2,3,13,14)$.

It further has been shown that parents do not want to 


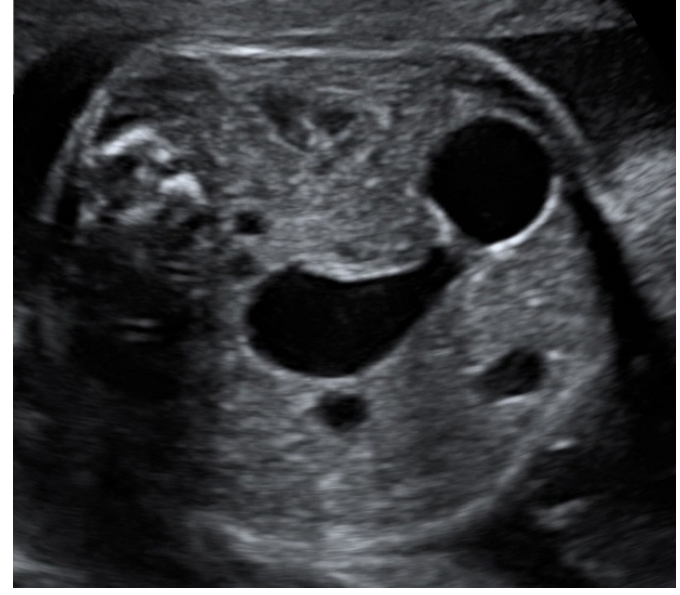

Figure 1 Typical ultrasound finding in duodenal atresia ("double bubble"), with a dilated stomach and proximal duodenum. High association with trisomy 21 .

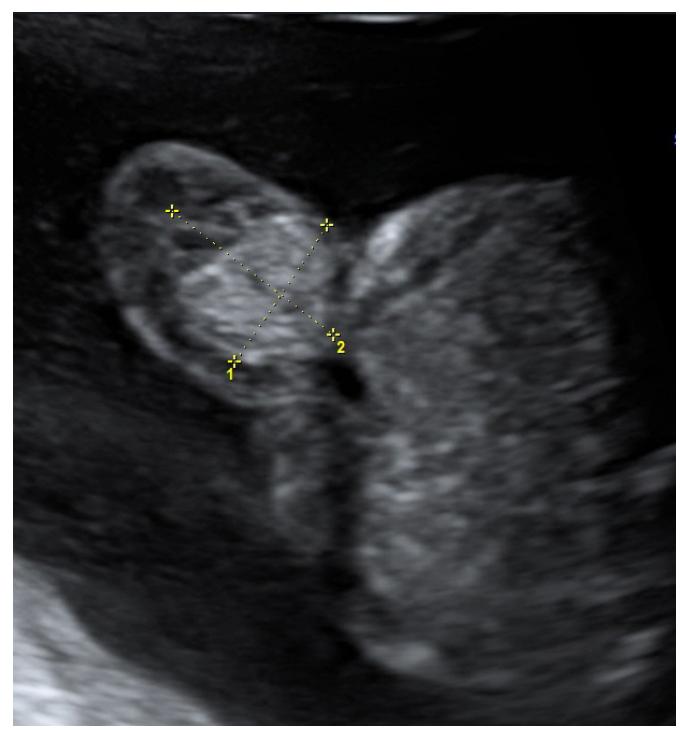

Figure 2 Small omphalocele with mainly fetal bowel $\left(1.8 \times 2.3 \mathrm{~cm}^{2}\right)$. In combination with $\mathrm{CHD}$ is a small omphalocele suspicious of trisomy 18. CHD, congenital heart disease.

wait - from their point of view unreasonably long-to see a specialist to confirm or exclude a suspected CHD in the fetus (14).

Parents prefer to be counseled in their native language (14). The effect of not being counseled in the native language has been shown by our group in terms of affecting negatively e.g. Transfer of Medical Knowledge, even if parental language skills are only mildly impaired $(2,3)$.
Very importantly one group has shown that parents who opted for termination of pregnancy (TOP) indicated that there generally is a lack of information on this option (13).

Finally, parents often need further support during pregnancy, e.g., by psychologists or social workers $(2,3,13)$.

\section{Parental emotional reactions after diagnosis of fetal CHD}

In particular mothers show signs of stress, depression and anxiety after a diagnosis of CHD in the unborn child (5). This is supported by data of postnatal evaluation of parents (22). But fathers are significantly affected as well (23). In contrast to the mothers, they often seek support from work environment. Mothers seem to benefit more from hospital-based resources. Healthy relationships between partners and existing coping strategies have been shown to be beneficial in the longterm. Psychological support may be crucial. Structured information on support systems, such as home-care services, should always be provided, e.g., by social workers already during hospital stay (23).

\section{Extra-cardiac diagnoses and genetic aspects}

In case of fetal CHD it is mandatory to examine the fetus for associated extra-cardiac malformations and asses the risk for genetic variations. Possible associated extracardiac malformations may include many organ systems: renal (agenesis, dysplasia) and gastrointestinal disease (Figure 1), abdominal wall defects (Figure 2), spine defects, and more (24). Suspected extra-cardiac malformations make it necessary to get a thorough overall view of the fetus. Counseling will then become challenging in an interdisciplinary setting where perinatal, neonatal and cardiac issues need to be considered. Associated genetic diseases include numerical chromosomal abnormalities, single gene disorders and genetic syndromes. The risk for additional genetic diseases is highly dependent on the type of CHD and varies from under $1 \%$ in simple Transposition of the Great Arteries up to $65 \%$ in Atrioventricular septal defects (25). Besides the typical numerical chromosomal abnormalities (Trisomy 13,18 and 21) there are single gene disorders like Noonan syndrome with a prevalence of 1:1,000 or more rare constellations like Holt-Oram and Alagille syndrome. Especially in CHD with conotruncal anomalies counseling should include the microdeletion syndrome DiGeorge/22q11, which has a wide clinical 


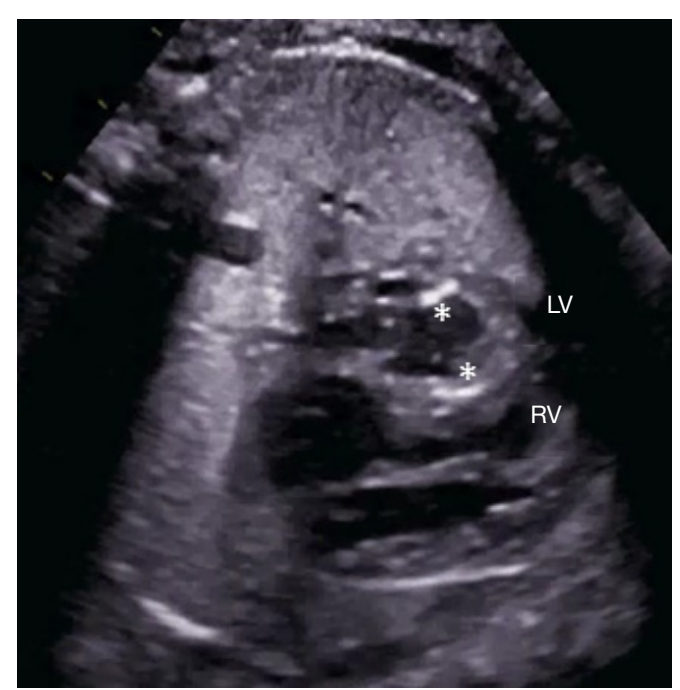

Figure 3 Fetal echocardiogram (four-chamber view): Hypoplastic Left Heart Syndrome (HLHS); hypoplastic LV with signs of endocardial fibroelastosis (* EFE). LV, left ventricle; RV, right ventricle.

variety and needs multidisciplinary counseling.

\section{Ethical issues}

Parental counseling should be conducted as close as possible after a first suspicion of fetal CHD. This has to be conducted by a specialist with significant experience in fetal hemodynamics, potential in-utero progression of CHD, immediate postnatal treatment, long-term aspects and potential sequelae ideally up to the young adult age.

Parental counseling for fetal CHD is a particular sensitive area where only experienced specialists should conduct at least the first conversations with the parents. The inexperienced trainee should be supervised (19).

Most professionals advocate non-directive counseling. It is very important not to impose personal bias into the discussion (15). The goal of an optimal counseling session -or multiple sessions - is that parents make an informed choice, which is best for them and their family. This includes discussion of TOP according to the country's legislation. The decision-making here is often affected by social, cultural and religious backgrounds.

\section{Counseling for univentricular heart disease}

In case of a fetal diagnosis of e.g., HLHS (Figure 3), counseling may be even more demanding due to increased mortality and morbidity compared to other CHD. Existing treatment options need to be provided, their outcomes and long-term aspects. Long-term sequelae, in particular neurodevelopmental issues, need to be discussed much more than in cases diagnosed with milder forms of CHD. Extra-cardiac factors such as growth restriction, preterm delivery or genetic syndromes may even have a stronger impact on overall prognosis. Current surgical approaches and local outcomes, but also in other centers, need to be discussed openly so that parents can choose where to deliver. In case of UV heart physiology, in particular with a dominant right ventricle, psychological support seems therefore even more relevant. The aim of counseling is to support parents so they understand their options to make an informed choice.

\section{Fetal cardiac interventions (FCIs) and counseling}

FCIs have been introduced into clinical practice without a trial. Therefore, indications are not based on randomized data, which makes counseling difficult. For other fetal therapies, such as endoscopic laser therapy for twin-totwin transfusion syndrome (TTTS), or intrauterine surgery for myelomeningocele, randomized studies have been performed and have led to modification of therapeutic approaches $(26,27)$. FCI are mainly performed for semilunar valve disease, such as critical aortic stenosis with evolving HLHS (Figure 4), critical pulmonary stenosis/ pulmonary atresia with intact ventricular septum (Figure 5), and in HLHS with a restrictive Foramen ovale (Figure 6) (28-33). In experienced centers with dedicated teams-after an initial learning curve-a survival advantage and more biventricular repairs have been shown for critical aortic stenosis with evolving HLHS $(29,33)$. However, there is a considerable risk for intrauterine death after the procedure, but also for preterm delivery $(28,32)$. In summary these interventions are still controversially discussed. While large FCI centers believe in the benefit of the procedure, some argue that improved postnatal treatment strategies do not justify continuation of FCI programs with in single centers reported fetal loss rates of $32 \%$ after FCI (32). This supports the concept of centralization for rare diagnoses and fetal interventions. If a diagnosis of fetal CHD is made and FCI seems worthwhile, the above-mentioned aspects need to be taken into account while counseling parents and offering a prenatal cardiac intervention. 


\section{Model of assessing counseling success}

To measure counseling success, our group used a validated questionnaire (1). It was developed by interdisciplinary cooperation (fetal and pediatric cardiologists, MFM specialists, sociologists), which we believe is extremely useful, not only to establish a research tool, but also for

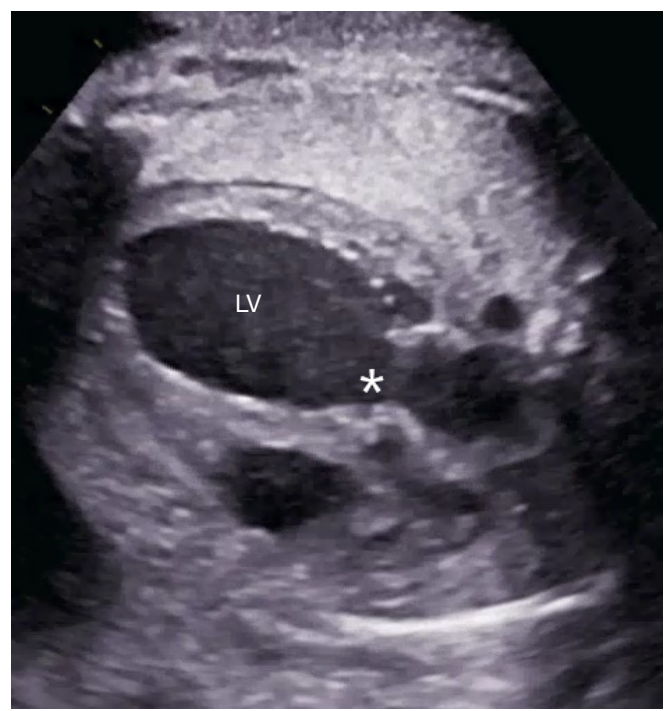

Figure 4 Fetal echocardiogram (four-chamber view): critical aortic stenosis: dilated left ventricle (LV) with severe $\mathrm{LV}$ dysfunction. *, thickened and dysplastic aortic valve. improving clinical services. Thus, we were able to cover not only medical, but also psychosocial and sociodemographic aspects comprehensively. Interdisciplinary concepts have been shown to be useful also in other medical specialties and have the potential of improving diagnostic and treatment strategies (34). In our studies involvement of social science has been proven to be extremely helpful as methodical expertise is very important to create, establish and validate research tools to cover a wide range of topics, and to analyze results comprehensively. For the questionnaire we used scaled and open questions, and asked for sociodemographic data. Assessment of counseling success as dependent variable was performed via five analytical dimensions: (I) "Transfer of Medical Knowledge"; (II) "Trust in Medical Staff”; (III) "Transparency Regarding the Treatment Process"; (IV) "Coping Resources"; (V) "Perceived Situational Control" (Figure 7). Questions on informational, temporal, spatial and social aspects were used as independent variables. Severity of CHD was graded and correlations calculated. We performed a multicenter national study, which seems unique for this topic (3). Some of our results add evidence to proposed guidelines from different associations $(4,19)$.

An adequate length of counseling-neither too short nor too long, without interruptions, and in a separate counseling room seems important for parents. But also providing additional written or web-based information, the latter ideally available in different languages, seems helpful, as even
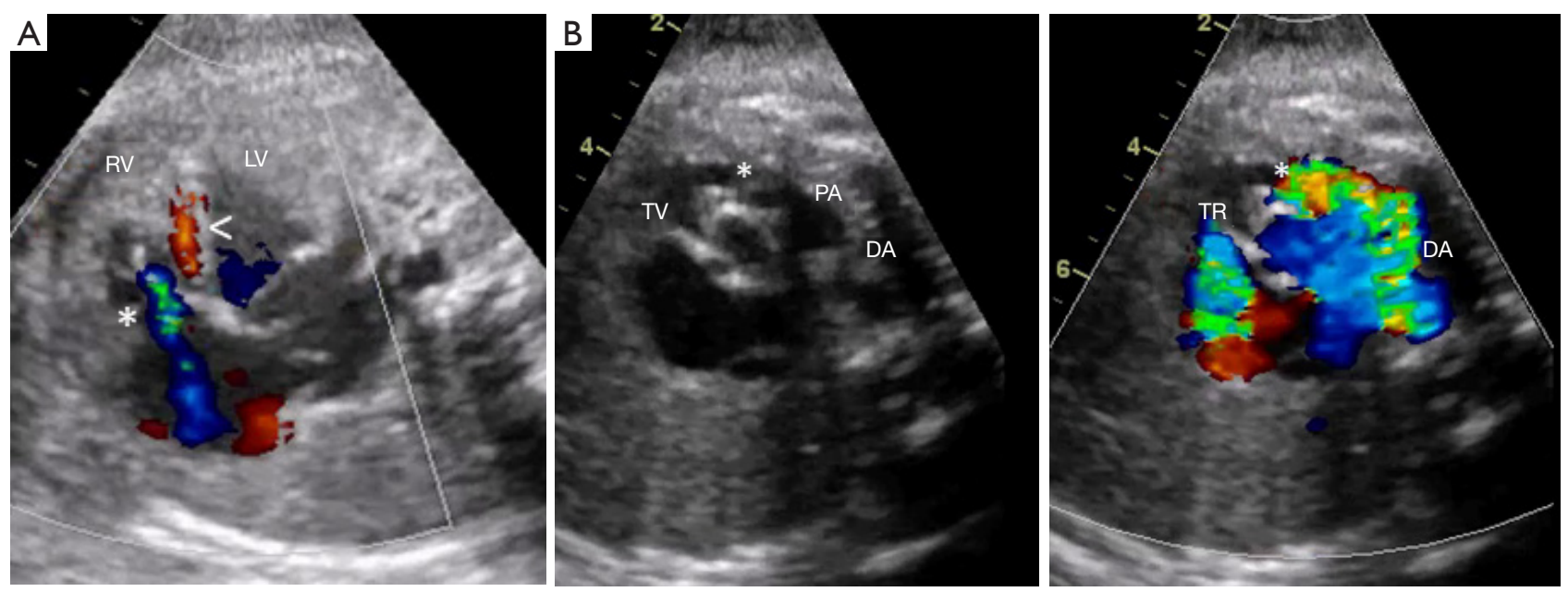

Figure 5 Fetal echocardiogram: pulmonary atresia with intact ventricular septum (PAIVS). (A) Four chamber view: right ventricle (RV) hypertrophied, poor systolic function; *, tricuspid regurgitation (TR); <, Coronary fistula. (B) Short-axis view (dual mode): *, thickened and dysplastic pulmonary valve, doming in systole without opening. Tricuspid valve (TV) with severe TR. Retrograde perfusion of the pulmonary trunk (PA) via the Ductus arteriosus (DA). 


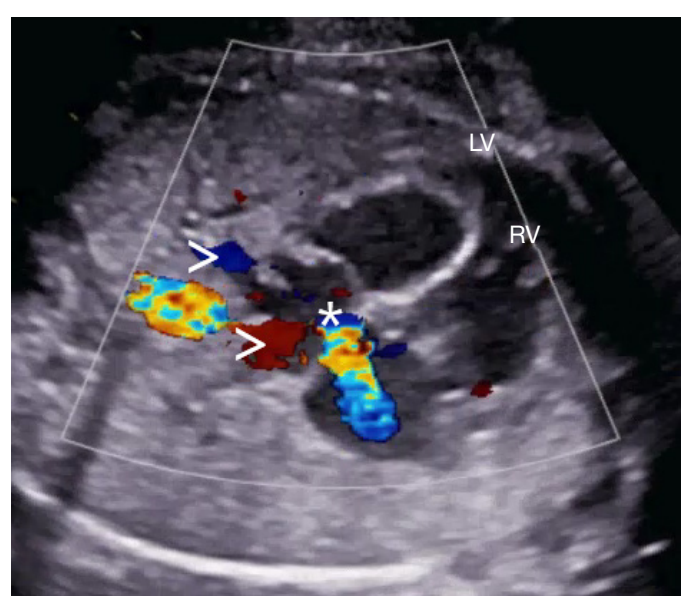

Figure 6 Fetal echocardiogram (four-chamber view): hypoplastic left heart syndrome (HLHS). Restrictive Foramen ovale (*, FO), and dilated pulmonary veins $(>)$. subtle parental language difficulties have a negative impact on overall counseling success and on all analytical dimensions.

Counseling by cardiologists seems essential, as in particular for complex CHD counseling success was impaired for selected dimensions.

Counseling success for parental "Perceived Situational Control" was further frequently impaired, showing thateven if offered on a regular basis-improved strategies for psychological support seem necessary.

Our approach may serve as paradigm to assess center specific performance, and to identify potential shortcomings in local programs, with the aim to improve services.

\section{Summary}

Complexity of parental counseling for fetal CHD differs

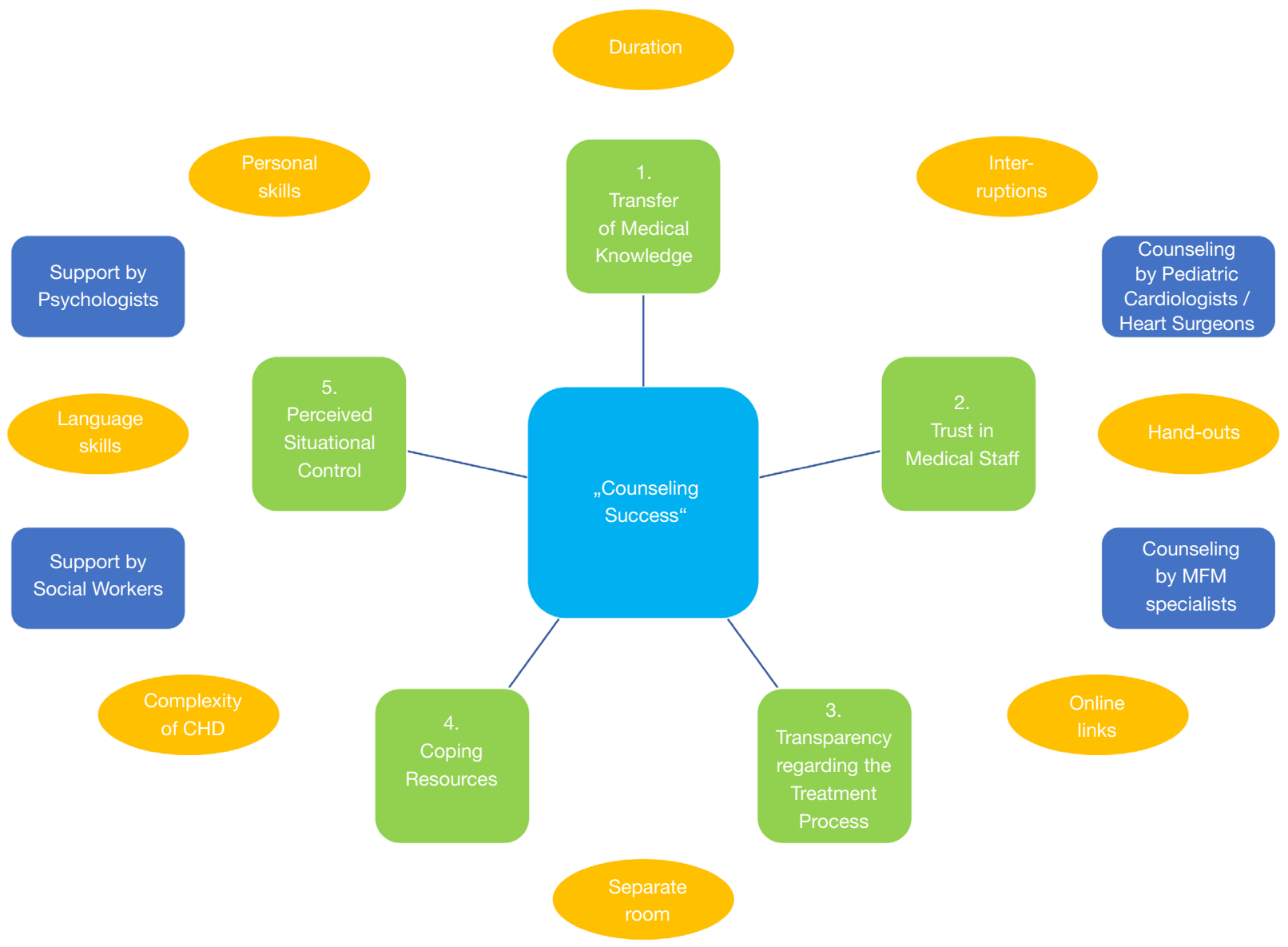

Figure 7 Model of assessing Counseling Success for fetal CHD. Overall counseling success may be assessed by five analytical dimensions: 1, "Transfer of Medical Knowledge"; 2, "Trust in Medical Staff”; 3, "Transparency Regarding the Treatment Process"; 4, "Coping Resources”; 5 , "Perceived Situational Control". Modifiers of counseling success in the dimensions and of overall counseling success are shown in the yellow circles and blue rectangles. 

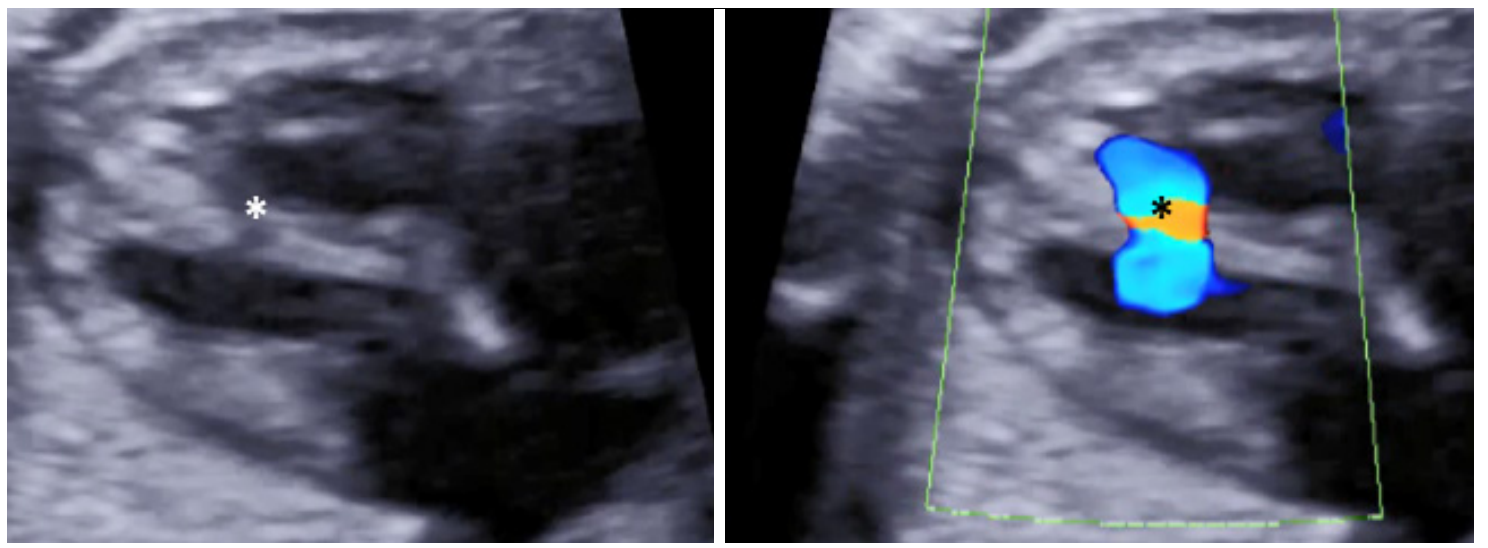

Figure 8 Muscular ventricular septal defect $\left(^{*}\right)$.

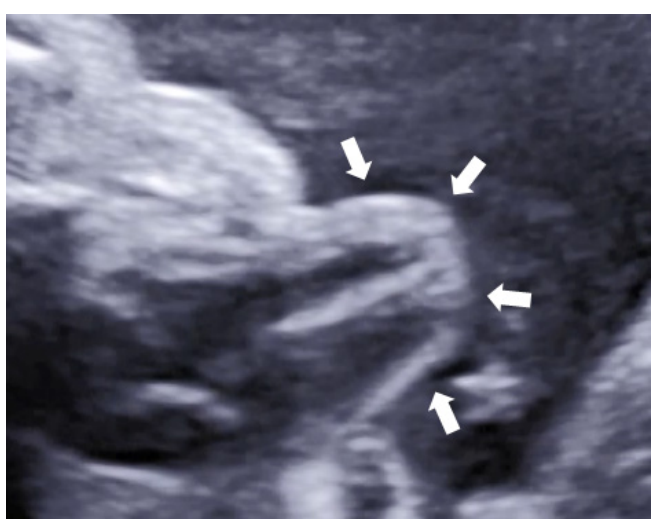

Figure 9 Ectopia cordis (arrows).

from case to case (Figures 8,9). It firstly may depend on the complexity of diagnosed heart defects, with variable postnatal outcomes (Figure 10), but also on potential extra-cardiac anomalies. Importantly, differing parental prerequisites and the consultants' skills are further modifiers of counseling success. Parental needs may result from educational, religious, cultural, and ethnic backgrounds. All this possibly affects effectiveness of counseling significantly, but also parental decision-making. The specialists need to be aware of these effects.

As there are rarely standards among tertiary Centers we recommend the following approach that may be considered useful to optimize a setting for counseling for fetal CHD.

Counseling by a specialist should always be offered shortly after the echocardiogram in a designated room. Interruptions should be avoided. Starting with open questions may be useful (e.g., "What do you understand so far regarding the cardiac diagnosis?"). Generally usage of easy and understandable terms is recommended to explain the CHD, treatment and prognostic aspects. Diagrams (printed or online) are usually helpful, also to compare findings with a normal heart for better understanding. Any diagnostic or therapeutic limitations must be outlined. The parents' understanding needs to be judged on a continuous basis during the conversation. If the counselor notices signs of uncertainty, counseling needs to be adapted accordingly. Also subtle language difficulties must be noted to offer timely counseling with an interpreter.

It may be useful to structure counseling sessions in two parts with a break in between. Whereas in part one, mainly medical information is transferred by the professionals, in part two primarily questions raised by the parents should be addressed. They should be encouraged to express their uncertainties, sorrows and fears. The break enables the parents to discuss in between and process the given information.

Finally written information and links to appropriate websites (ideally available in the parents' native language) should be provided. Follow-up appointments, also to see, e.g., geneticists, cardiac surgeons, or others such as psychologists, need to be arranged depending on the diagnoses and parental wishes. Contact data of cardiac specialist nurses, support-groups, or parents' associations should further be offered. This approach should also aid to preserve long-term psychological health of parents.

\section{Conclusions}

Parental counseling for fetal heart defects is multidimensional, and requires significant expertise. 

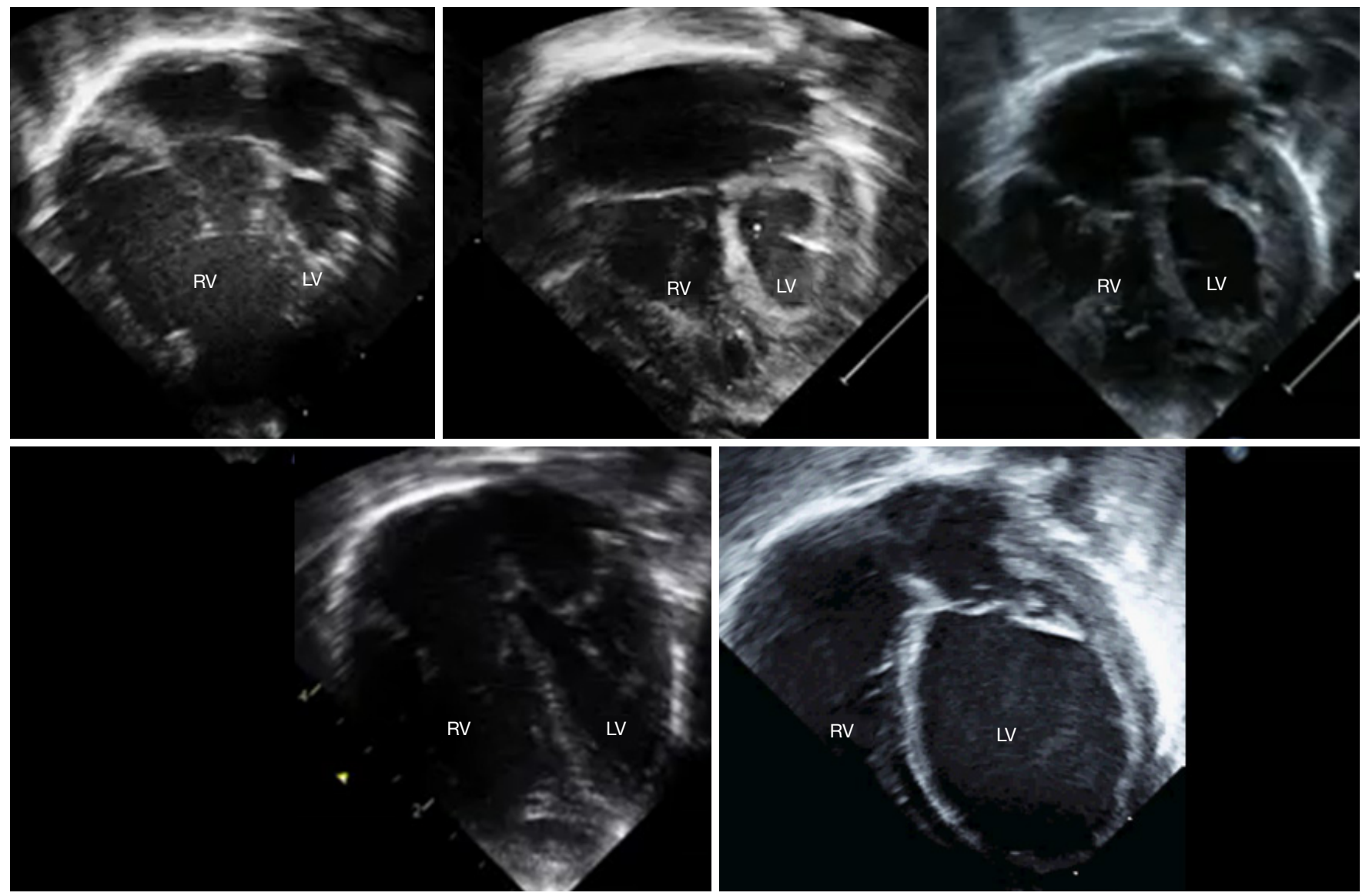

Figure 10 Echocardiograms (four-chamber view) of newborns (pre-procedural) diagnosed with fetal aortic stenosis displaying the spectrum of postnatal outcomes.

This includes not only experience in fetal and pediatric cardiology regarding the in-utero physiology and potential progression of $\mathrm{CHD}$, immediate postnatal treatment, longterm aspects and sequelae up to the young adult age, but also communicative skills. Generally, a structured approach may lead to more effective counseling. However, in addition specific training to improve communication skills should be implemented on a regular basis. Interdisciplinary concepts have been proven to be extremely useful not only for research purposes but also to improve medical services such as fetal cardiac care programs. Different studies including our own investigations add further evidence to published guidelines by different international societies. Combined, these data offer valuable strategies to improve local services.

\section{Acknowledgments}

Funding: None.

\section{Footnote}

Provenance and Peer Review: This article was commissioned by the Guest Editor (Antonio F. Corno) for the series "Pre-natal Diagnosis in Congenital Heart Defects" published in Translational Pediatrics. The article has undergone external peer review.

Conflicts of Interest: The authors have completed the ICMJE uniform disclosure form (available at http://dx.doi. org/10.21037/tp-20-181). The series "Pre-natal Diagnosis in Congenital Heart Defects" was commissioned by the editorial office without any funding or sponsorship. SB reports grants from Ministry of Social Affairs BadenWürttemberg, grants from HeiKaExplore (Heidelberg Karlsruhe Strategic Partnership), outside the submitted work. The other authors have no other conflicts of interest to declare. 
Ethical Statement: The authors are accountable for all aspects of the work in ensuring that questions related to the accuracy or integrity of any part of the work are appropriately investigated and resolved.

Open Access Statement: This is an Open Access article distributed in accordance with the Creative Commons Attribution-NonCommercial-NoDerivs 4.0 International License (CC BY-NC-ND 4.0), which permits the noncommercial replication and distribution of the article with the strict proviso that no changes or edits are made and the original work is properly cited (including links to both the formal publication through the relevant DOI and the license). See: https://creativecommons.org/licenses/by-nc-nd/4.0/.

\section{References}

1. Kovacevic A, Simmelbauer A, Starystach S, et al. Assessment of needs for counseling after prenatal diagnosis of congenital heart disease - a multidisciplinary approach. Klin Padiatr 2018;230:251-6.

2. Kovacevic A, Simmelbauer A, Starystach S, et al. Counselling for prenatal congenital heart disease Recommendations based on empirical assessment of counselling success. Front Pediatr 2020;8:26.

3. Kovacevic A, Bär S, Starystach S, et al. Objective Assessment of Counselling for Fetal Heart Defects: An Interdisciplinary Multicenter Study. J Clin Med 2020;9:467.

4. Donofrio MT, Moon-Grady AJ, Hornberger LK, et al. Diagnosis and treatment of fetal cardiac disease: a scientific statement from the American Heart Association. Circulation 2014;129:2183-242.

5. Rychik J, Donaghue DD, Levy S, et al. Maternal Psychological Stress After Prenatal Diagnosis of Congenital Heart Disease. J Pediatr 2013;162:302-7.e1.

6. Field T, Diego M, Hernandez-Reif M, et al. Pregnancy anxiety and comorbid depression and anger: effects on the fetus and neonate. Depress Anxiety 2003;17:140-51.

7. Field T. Prenatal depression effects on early development: a review. Infant Behav Dev 2011;34:1-14.

8. Mulder EJH, Robles de Medina PG, Huizink AC, et al. Prenatal maternal stress: effects on pregnancy and the (unborn) child. Early Hum Dev 2002;70:3-14.

9. Weinstock $M$. The potential influence of maternal stress hormones on development and mental health of the offspring. Brain Behav Immun 2005;19:296-308.

10. Talge NM, Neal C, Glover V. Early Stress, Translational
Research and Prevention Science Network: fetal and neonatal experience on child and adolescent mental health. Antenatal maternal stress and long-term effects on child neurodevelopment: how and why? J Child Psychol Psychiatry 2007;48:245-61.

11. Huizink AC, Robles de Medina PG, Mulder EJH, et al. Stress during pregnancy is associated with developmental outcome in infancy. J Child Psychol Psychiatry 2003;44:810-8.

12. Arya B, Glickstein JS, Levasseur SM, et al. Parents of children with congenital heart disease prefer more information than cardiologists provide. Congenit Heart Dis 2013;8:78-85.

13. Carlsson T, Bergman G, Wadensten B, et al. Experiences of informational needs and received information following a prenatal diagnosis of congenital heart defect. Prenat Diagn 2016;36:515-2.

14. Bratt EL, Järvholm S, Ekman-Joelsson BM, et al. Parent's experiences of counselling and their need for support following a prenatal diagnosis of congenital heart diseaseA qualitative study in a Swedish context. BMC Pregnancy Childbirth 2015;15:171.

15. Malhotra A, Menahem S, Gillam L. Ethical issues in fetal management: A cardiac perspective. Int J Pediatr 2010;2010:857460.

16. Menahem S, Grimwade J. Counselling strategies in the prenatal diagnosis of major heart abnormality. Heart Lung Circ 2004;13:261-5.

17. Walsh MJ, Verghese GR, Ferguson ME, et al. Counseling Practices for Fetal Hypoplastic Left Heart Syndrome. Pediatr Cardiol 2017;38:946-58.

18. Nell S, Wijngaarde CA, Pistorius LR, et al. Fetal heart disease: Severity, associated anomalies and parental decision. Fetal Diagn Ther 2013;33:235-40.

19. Allan L, Dangel J, Fesslova V, et al. FRecommendations for the practice of fetal cardiology in Europe. Association for European Paediatric Cardiology. Cardiol Young 2004;14:109-14.

20. Paladini D, Alfirevic Z, Carvalho JS, et al. Prenatal counseling for neurodevelopmental delay in congenital heart disease: results of a worldwide survey of experts' attitudes advise caution. Ultrasound Obstet Gynecol 2016;47:667-71.

21. Paladini D, Alfirevic Z, Carvalho JS, et al. ISUOG consensus statement on current understanding of the association of neurodevelopmental delay and congenital heart disease: Impact on prenatal counseling. Ultrasound Obstet Gynecol 2017;49:287-8. 
22. Bevilacqua F, Palatta S, Mirante N, et al. Birth of a child with congenital heart disease: emotional reactions of mothers and fathers according to time of diagnosis. J Matern Fetal Neonatal Med 2013;26:1249-53.

23. Sood E, Karpyn A, Demianczyk AC, et al. Mothers and Fathers Experience Stress of Congenital Heart Disease Differently: Recommendations for Pediatric Critical Care. Pediatr Crit Care Med 2018;19:626-34.

24. Copel JA, Pilu G, Kleinman CS. Congenital heart disease and extracardiac anomalies: associations and indications for fetal echocardiography. Am J Obstet Gynecol 1986;154:1121-1132.

25. Harris JA, Francannet C, Pradat P, et al. The epidemiology of cardiovascular defects, part 2: a study based on data from three large registries of congenital malformations. Pediatr Cardiol 2003;24:222-35.

26. Adzick NS, Thom EA, Spong CY, et al. A randomized trial of prenatal versus postnatal repair of myelomeningocele. N Engl J Med 2011;364:993-1004.

27. Senat MV, Deprest J, Boulvain M, et al. Endoscopic laser surgery versus serial amnioreduction for severe twin-to-twin transfusion syndrome. N Engl J Med 2004;351:136-44.

28. Kovacevic A, Öhman A, Tulzer G, et al. Fetal hemodynamic response to aortic valvuloplasty and postnatal outcome: a European multicenter study. Ultrasound Obstet Gynecol

Cite this article as: Kovacevic A, Elsässer M, Fluhr H, Müller A, Starystach S, Bär S, Gorenflo M. Counseling for fetal heart disease-current standards and best practice. Transl Pediatr 2021;10(8):2225-2234. doi: 10.21037/tp-20-181
2018;52:221-9.

29. Friedman KG, Sleeper LA, Freud LR, et al. Improved technical success, postnatal outcome and refined predictors of outcome for fetal aortic valvuloplasty. Ultrasound Obstet Gynecol 2018;52:212-20.

30. Tulzer A, Arzt W, Gitter R, et al. Immediate effects and outcome of in-utero pulmonary valvuloplasty in fetuses with pulmonary atresia with intact ventricular septum or critical pulmonary stenosis. Ultrasound Obstet Gynecol 2018;52:230-7.

31. Moon-Grady AJ, Morris SA, Belfort M, et al. International Fetal Cardiac Intervention Registry. International Fetal Cardiac Intervention Registry: A Worldwide Collaborative Description and Preliminary Outcomes. J Am Coll Cardiol 2015;66:388-99.

32. Galindo A, Gómez-Montes E, Gómez O, et al. Fetal Aortic Valvuloplasty: Experience and Results of Two Tertiary Centers in Spain. Fetal Diagn Ther 2017;42:262-70.

33. Arzt $W$, Wertaschnigg D, Veit I, et al. Intrauterine aortic valvuloplasty in fetuses with critical aortic stenosis: experience and results of 24 procedures. Ultrasound Obstet Gynecol 2011;37:689-95.

34. Bertsche T, Neininger MP, Kaune A, et al. Interdisciplinary Concepts of Paediatrics and Clinical Pharmacy to Optimise Anticonvulsant Treatment. Klin Padiatr 2018;230:5-12. 